\begin{tabular}{|c|c|c|}
\hline 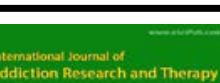 & & 高然能证回 \\
\hline$=: \min _{n}$ & International Journal of Addiction Research and Therapy & 知地 \\
\hline 年 & (ISSN:2637-8795) & 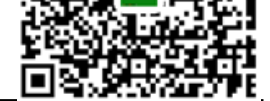 \\
\hline
\end{tabular}

\title{
CANNABINOID POISONING IN CHILDREN: IMPORTANCE OF MULTIDRUG TESTING
}

\author{
Waleska Ramos Souza ${ }^{*}$, Cinthya Maria Pereira ${ }^{2}$ \\ UNIFACISA ${ }^{1}$, Teacher Dra of the Pharmacy Course UNIFACISA ${ }^{2}$
}

\begin{abstract}
Introduction: Cannabis sativa is one of the most commonly used recreational drugs, contains over 500 different clinical compounds and over 60 known cannabinoids. Drug abuse tests are widely used as hospital screening tests for poisoning diagnoses. Objective: This study aims to understand the types of drug abuse tests used in cases of acute cannabinoid poisoning, especially in children.
\end{abstract}

Methodology: This was a literature review, having as source of research the databases UpToDate, NCBI Pubmed, Online Library (SCIELO) and Toxicology Manuals. As inclusion criteria were used publications from 2000 to 2019, in Portuguese, English and Spanish, related to the keywords.

Discussion: Acute cannabis poisoning is a clinical diagnosis, however, diagnosis in children may be difficult, so drug screening in the urine may be helpful to confirm the diagnosis.

Conclusion: These tests are easy to perform and cheap, having good specificity through their chemical structure, directing the immunoassay to the toxic agent.

Keywords: cannabis sativa, accidents, toxic agent.
*Correspondence to Author:

Waleska Ramos Souza

UNIFACISA

How to cite this article:

Waleska Ramos Souza, Cinthya Maria Pereira. CANNABINOID POISONING IN CHILDREN: IMPORTANCE OF MULTIDRUG TESTING. International Journal of Addiction Research and Therapy, 2020, 3:14

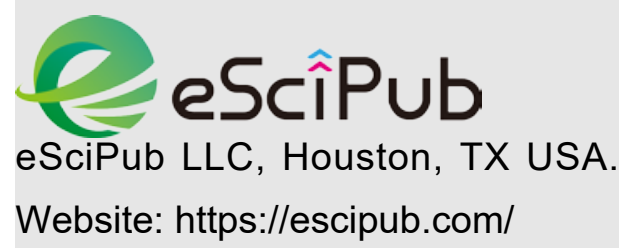




\section{INTRODUCTION}

Cannabis sativa is one of the most commonly used recreational drugs, containing over 500 different clinical compounds and over 60 known cannabinoids. Of these, delta-9 tetrahydrocannabinol (THC) is responsible for most intoxication symptoms ${ }^{7}$. According to the World Health Organization ${ }^{6}, 147$ million people, or $2.5 \%$ of the world's population, use cannabis (marijuana), as of 2018 nine states have allowed the sale and possession of recreational marijuana, making it the most illicit substance widely cultivated, trafficked and abused in the world. Both decriminalization and legalized recreational use have been associated with increased unintentional pediatric ingestion through ingested (sweet food) and vaporized (passive inhalation) forms representing a risk of intoxication ${ }^{5}$.

Drug abuse tests are immunochromatographic tests using single or multi-drug reagent strips. The basic test screen shows five drug classes: amphetamine, cocaine, marijuana, opioids, phencyclidine (PCP) or benzodiazepines. Tests included on other basic screens may vary by medical facility, region, and country-specific ${ }^{3}$. Although many drugs used are undetected, such as newly developed, plant-derived or synthesized amphetamines (synthetic cannabinoids), they are widely used as hospital screening tests for diagnoses in cases of poisoning.

\section{OBJECTIVE}

Given the social and clinical aspects, understanding of drug abuse testing is of paramount importance especially in cases of acute cannabinoid poisoning in children.

\section{METHODOLOGY}

This is a bibliographical, descriptive and qualitative review, which had as source of research the databases UpToDate, NCBI Pubmed, Online Library (SCIELO) and Toxicology Manuals. As search descriptors the following terms were used: intoxication, drugs of abuse, recreational use, cannabis sativa, and the inclusion criteria of the articles were those published from 2000 to 2019, in Portuguese, English and Spanish, related to keywords.

\section{DISCUSSION}

Studies point out that as cannabis legalization has been authorized, intoxication cases have increased, making it an important factor for knowledge of cannabinoid drug testing. According to $\mathrm{Wag}^{7}$, when concentrated hashish resin became more available in France, a corresponding increase in the number and severity of annual hospitalizations occurred among infants and young children as well as after legalizing recreational marijuana use in Colorado, annual calls Regional Center for Pediatric Marijuana Control increased $34 \%$ on average to 6 cases per 100,000 population, which was almost double the rate for the rest of the United States.

Epidemiological data describe exposure to oral ingestion, either by the use of highly concentrated food or incentive or passionate inhalation. Noroya and collaborators ${ }^{5}$ report a picture of poisoning by an 8-year-old girl after eating a chocolate cake containing cannabis flowers ("buds") made by a 22-year-old brother. Hospitalization is seen more in children than in adults, with toxic doses being poorly defined, depending on the degree of signs and symptoms. Heizer JW et al ${ }^{2}$ define an estimated dose requiring hospitalization $7.13 \mathrm{mg} / \mathrm{kg}$, but $3.2 \mathrm{mg} \mathrm{/} \mathrm{kg}$ THC led to minimal medical observation and intervention.

Clinical determination is a crucial point for the confirmation of the toxic agent and for the possible therapeutic approaches. Cannabinoid poisoning in children has acute neurological symptoms marked by drowsiness, lethargy, hyperactivity, irritability, agitation, confusion, mydriasis, nausea and vomiting, sympathomimetic effects (tachycardia and hypertension). Bradycardia \hypotension and seizures may occur, being less seen. Overdoses (large intakes of concentrates) may occur with apnea or depressed breathing. Slurred speech, 
red eyes, inattention, and concentration are all clear signs of cannabinoid poisoning ${ }^{2-5-7}$

Regardless of age, acute cannabis poisoning is a clinical diagnosis. However, diagnosis in the pediatric population can be difficult because a history of exposure is often lacking and the symptoms of marijuana exposure are nonspecific. Thus, drug screening in urine may be useful to confirm the diagnosis because any positive result in children identifies acute exposure ${ }^{7}$. Proper interpretation of results should take into consideration the type of test to be performed, the level of suspicion for drug use or exposure (ie, pretest probability), the purpose of obtaining the test, and the likelihood of false positive and false negative results ${ }^{3}$

Immunoassays are typically the initial screening test used to detect the presence of drugs of abuse or metabolite. Usually providing a result within minutes of sample application, being able to detect low concentrations of a substance with a high degree of specificity, are technically easy to perform and relatively inexpensive ${ }^{2}$. The major marijuana metabolite (11-Nor-9-carboxydelta-9-tetrahydrocannabinol, $\mathrm{THCCOOH}$ ) can be found in a child's urine to confirm exposure. This metabolite can be detected for more than seven days after acute exposure and offers preliminary results. The specificity of the test helps exponentially in the diagnosis, because the chemical structure is unique and the immunoassays are directed to THC metabolites, making rare false positive results and very recurrent use in hospitals ${ }^{4}$.

Confirmation techniques allow unambiguous identification of the substance, such as mass spectrometer-coupled gas chromatography (GC / MS), or mass spectrometer-coupled liquid chromatography (LC / MS) that allows additional identification, however, test results confirmatory findings do not return quickly enough to affect clinical care ${ }^{3}$.

A second test can also be used, point-of-care (POC) tests using urine or saliva perform poorly than manufacturers, particularly for marijuana / cannabinoid detection, in the case of the departmental POC test. In emergencies or clinical testing, errors in technique and interpretation are more likely, thus requiring specific training for collection and interpretation ${ }^{1}$. In both tests they do not detect synthetic cannabinoids and the presence of the drug or metabolite does not necessarily indicate active intoxication, as the drugs can be detected at levels that do not cause clinical effects.

\section{FINAL CONSIDERATIONS}

Thus, we can conclude that drug abuse tests used to detect the active metabolite of cannabis sativa is an important tool for rapid detection of toxic agents, especially in children, who have more severe clinical manifestations. These tests are easy to perform and cheap, having good specificity through their chemical structure, directing the immunoassay to the toxic agent and confirming the signs and symptoms present. However, with the increase in synthetic drugs, this test may not direct the sample to a possible substance other than natural cannabinoids, making the diagnosis fully clinical.

\section{REFERENCES}

1. Arkell TR, Kevin RC, Stuart J, et al. Detection of $\triangle 9 \mathrm{THC}$ in oral fluid following vaporized cannabis with variety cannabidiol (CBD) content: An evaluation of two point-ofcollection testing devices. Drug Test Anal. 2019; 1-12.

2. HEIZER JW et al; Marijuana Misadventures: Exploring a Dose-Response Relationship and Summary of Clinical Effects and Results. Pediatr Emerg Care. 2018; 34 (7): 457-462.

3. HOFFMAN, R.J .; TRAUB, Dr.S .; GRAYZEL, $\mathrm{J}$.; Drug Abuse Test (DOA). UpToDate. 2019. [Accessed 23 Aug 2019] Available: https://www.uptodate.com/contents/testingfor-drugs-of-abuse-

doa?search=cannabis\%20sativa\%20and\%20 use \%20recreativo\&source=search_result\&se lectedTitle $=10 \sim 150 \&$ usage_type $=$ default $\&$ display_rank $=10$.

4. Clinical Toxicology Manual: Guidelines for care and surveillance of acute poisoning. Sao Paulo: Municipal Health Secretariat, 2017: 97102.

5. NOROYA, $\mathrm{N}$ et al. Unintentional exposure to cannabis in children under the regulation of cannabis sales in Uruguay. Report of cases 
Waleska Ramos Souza et al., IJART, 2020 3:14

treated at the Emergency Service of Pereira

Rossell Hospital between March and June 2017. Arch. Pediatrician 2018; 89 (5).

6. WORLD HEALTH ORGANIZATION (WHO). Management of substance abuse: Cannabis

[Lit 26 Aug 2019] Available: www.who.int/substance_abuse/facts/cannabi s/en/.

7. WANG, G. S. et al; Cannabis (Marijuana): acute intoxication. UpToDate. 2019. [Accessed 23 Aug 2019]. Available: https://www.uptodate.com/contents/cannabis -marijuana-acute-

intoxication?sectionName=Drug $\% 20$ testing\%20for\%20cannabinoids \&search=can nabis\%20sativa\%20and\%20uso\% 20recreative \& topicRef $=13846 \&$ anchor $=$ H7892848 \& source = see_link \# H7892848. 